\title{
Cost variation in child and adolescent psychiatric inpatient treatment
}

\author{
Jennifer K. Beecham · Jonathan Green • \\ Brian Jacobs · Graham Dunn
}

Received: 13 October 2008/Accepted: 13 February 2009/Published online: 14 March 2009

(c) Springer-Verlag 2009

\begin{abstract}
Publicly available costs data for child and adolescent psychiatric inpatient services do not allow links to be made with patients' needs and outcomes. Without this information commissioners may reduce the role of inpatient services on the basis of budgetary impacts alone. This study estimates the support costs before, during and after an inpatient admission and explores the associations between costs, needs and outcomes. A detailed prospective cohort study of eight child and adolescent units was undertaken in which participants were assessed at referral, admission, decision to discharge and 1 year later. Mean admission costs were $£ 24,120$, although the range was wide. Associations were found between costs and patients' global impairment, age and exclusion status. Support costs after admission were similar to pre-admission costs, but there was some evidence to suggest that services were better targeted. Moves in England to develop national
\end{abstract}

J. K. Beecham ( $\square)$

PSSRU, University of Kent, Canterbury, Kent CT2 7NF, UK

e-mail: J.K.Beecham@kent.ac.uk

J. K. Beecham

PSSRU, London School of Economics,

Houghton Street, London WC2 2AE, UK

J. Green

Academic Department of Child and Adolescent Psychiatry,

Lane Building, Booth Hall Children's Hospital, Blackley,

Manchester M9 7AA, UK

B. Jacobs

Department of Child and Adolescent Psychiatry,

Maudsley Hospital, Denmark Hill, London SE5 8AZ, UK

G. Dunn

School of Community Based Medicine, University of

Manchester, Oxford Road, Manchester M12 9PL, UK tariffs for inpatient psychiatric episodes should be based on the likely cost of the episode of treatment rather than costs per day, and good commissioning requires more information on the predictors of such costs.

Keywords Child and adolescent psychiatric inpatient units $\cdot$ CAMHS $\cdot$ Cost $\cdot$ Cost analysis

\section{Introduction}

Child and adolescent mental health (CAMH) inpatient services in England are complex and diverse, and admission is reserved for the most serious and complex cases. CAMH inpatient services are considered to be specialised services for commissioning purposes [11]. All but emergencies require commissioners from the originating community service to agree to fund the admission. Each inpatient service is funded through different forms of commissioning contract, from cost per case to more general service-level agreements. While there are plans to move towards developing national tariffs for specialist services [12], little is known about the costs of CAMH inpatient care episodes, the associations between costs and needs or the extent to which inpatient treatment has implications for subsequent use of education, health or social care services.

\section{Methods}

Design

A detailed prospective cohort study of consecutive and unselected admissions to four child and four adolescents units was undertaken [18]. Two of each type of unit were in 
the north of England and two in the south, representing the geographic and demographic spread of units and mainstream NHS practice. Young people were assessed at referral, at admission and on decision to discharge, and followed-up 1 year after discharge. Assessments included discrete symptoms and global impairments using methods validated in previous studies $[17,25]$ as well as service use.

\section{Sample}

A total of 155 consecutive admissions were referred to the study over a 15-month-period ending April 2002. This economic study used data from the pre-admission assessments ( $n=150)$, the interviews at discharge from hospital $(137 ; 91 \%)$ and the interviews at 1 year after discharge $(117 ; 78 \%)$. Onset of symptoms occurred at a median of 18 months prior to admission (range 0-180 months). Using the KSADS [22], researchers found that $57 \%$ of patients had two or more DSM-IV diagnoses and $29 \%$ had three or more: major depressive disorder (43\%), oppositional defiant disorder (27\%), attention deficit/hyperactivity disorder $(19 \%)$, conduct disorder $(17 \%)$, post-traumatic stress disorder $(11 \%)$, pervasive developmental disorder (10\%) and psychosis (6\%) [18].

Full information on service use, the basis for the cost estimations, was available for 132 young people at preadmission ( $88 \%$ of the interviewed sample), 131 young people at discharge from the ward $(96 \%), 83$ at the follow-up (70\%) and for 74 young people at all three study points. Data on the use of education services were most commonly missing. There were no significant differences in baseline or index admission costs between the 74 young people with full data and those for whom followup data were not available $(P<0.24)$. The groups were also similar in age and symptom scores, although the "costs sample" (those with full information on service use) scored around six points higher (less impaired) on the Children's Global Assessment Scale at admission $(P=0.049)$.

\section{Measures}

Data on service use were collected from parents using a specially adapted Client Service Receipt Inventory (CSRI) [3] for 6 months pre-admission, during the admission and 6 months before the 1-year follow-up. The retrospective period selected for the follow-up allows direct comparison with the pre-admission data and represents "steady-state" service use (avoiding high or low use immediately following hospital discharge) and balances recall accuracy with the potential to include less frequently used services, such as hospital re-admission.
Costs were estimated as the best approximation of their long-run marginal opportunity cost [2, 23]. Unit costs for most services were taken from an annual compendium [9] or estimated with an equivalent methodology using publicly available data or information from provider agencies. The unit cost for each service was multiplied by each young person's pattern of use and total and component costs for their support package calculated. All health, education, social care and youth justice supports provided by the public or independent sectors were included. All but one participant lived at home (eight were adopted). To reflect the period when most young people were in the study, we used the prices of 2001-2002. Costs can be estimated at the 2006-2007 prices (latest available) by applying the Hospital and Community Health Services index (1.2) [8]. To adjust sterling to international dollars for 2007, prior to recent volatility in exchange rates, a multiplier of 1.543 should be applied based on 0.648 of purchasing power parity for UK sterling in that year [21].

The average unit cost for each study ward was estimated separately and included all ward staff (including teaching), running costs, as well as overheads accruing to the organisation, buildings and equipment [5]. There have been no radical changes to inpatient services or the clinical care within those services in the intervening period, nor have referral patterns changed substantially [1]. There were no inputs from outside agencies, except local authority funding for the on-site school. The number of days that each young person spent in the ward during the index admission was calculated from detailed individualised ward-staff reports, taking into account ward closures at the weekend and clinical decisions on home leave. This "days on ward" measure is used to calculate the costs of the inpatient service received. Only $13 \%$ (17/131) of young people were day patients and $15 \%$ spent part of the admission as day patients, usually as part of their discharge plan.

Based on the availability of data for this sample, the outcome analysis and previous research on variations in the cost per day for CAMH inpatient units, the following variables were hypothesised to have an influence on costs [4, 18].

- Gender, age at admission and younger than 13 years old. Ethnicity was self-rated as white for $94 \%$ and only nine patients were subject to a legal order; neither variable was included in the analyses.

- Accommodation (rented or owner-occupied), single parent household, family's main income source (employment or social security benefits), exclusion from school or regular school attendance (more than 3 days per week) in the previous year and having a Statement of Educational Need. 
- Total scores from the Children's Global Assessment Scale (GCAS) [30] provided a standardised measure of global impairment.

- Sub-scores from the Salford Needs Assessment for Adolescents (SNASA) [26] for risky behaviour, aggression, externalising behaviour, pervasive developmental disorder, deliberate self-harm, and eating and mood problems.

- Parental reports of life events (for example, birth of another child, moving house, death in the family, divorce, separation, etc.) and parental reports of duration and severity of illness.

- Change in CGAS scores and for the SNASA items between admission, discharge and follow-up (clinical outcomes).

Once cost associations with the above variables had been established through the regression equations, the following service-related variables were tested: type of admission (emergency or planned); ward location (north or south of England); ward type (child or adolescent); and an identifier for each ward. For the follow-up cost analysis, the list of potential predictors was extended to include length of index admission, number of days spent in the ward and admission cost.

Analysis

For cost comparisons and bivariate associations with costs, $t$ tests are reported with the results confirmed using bootstrapped confidence intervals (1,000 repetitions) [15]. Anova was used for continuous variables. To help disentangle the complex associations between the costs and potential explanatory variables, we used ordinary least squares linear regression with robust standard errors to control for heterogeneity within wards [13, 24]. Each of the reported equations used observed costs as the dependent variable, but the standardised residuals were normally distributed. A logarithmic transformation of costs was also investigated and the results were similar, with the variables and directions of influence unchanged. The significance of the independent variables entering the equations was confirmed using bootstrapped confidence intervals.

\section{Results}

Pre-admission cost associations

Table 1 shows the service use patterns for the 6 months prior to the index admission. Sample members were aged between 3.4 and 17.6 years; seven were too young to attend school. Less than a quarter used educational psychology support. Over a third had inpatient admissions, of which 55/62 were for mental health problems. Half the young people were in contact with community-based CAMH services and a quarter had outpatient appointments. A quarter had contact with a social worker.

The average total support costs per person were $£ 4,207$ (SD 4,037) for the 6-month-period, around three times higher than the costs found in a study of children with behavioural problems [19]. There were very few associations between pre-admission costs and the potential explanatory variables. The best significance values were obtained for the SNASA measure of risky behaviour $(P=0.045)$ and the referrers' CGAS score $(P=0.050)$ resulting in a low $R^{2}$ (proportion of variance explained statistically $=0.03$ ). Prior to admission, therefore, service use (as summarised by costs) was not associated with young people's characteristics, family circumstances, mental health problems, etc.

Cost associations during the index admission

On average, admissions lasted for 116 days, of which 26 were spent away from the unit on home leave (Table 2). Using the "days on ward" measure, mean episode costs were $£ 24,123$ per child (median $£ 19,495$ ). There is a positive skew with ten young people having relatively high admission costs. Costs for a quarter of the sample were under $£ 9,900$ and a quarter cost over $£ 31,700$. Ward 7 showed significantly lower admission costs than Ward 4 $(P=0.005)$ or Ward $8(P=0.001)$. Compared to other wards, Ward 7 undertook a higher number of time-limited assessments for children with autism during the study period.

The bi-variate analyses (Table 3) show that lower admission costs are associated with younger age, residence on a child ward and exclusion from school prior to admission. Controlling for potential clustering by ward led to the age-related variables becoming non-significant, but school exclusion remained negatively associated $(P=0.038 ; \mathrm{CI}=-15,759,-573)$. Higher index admission costs were associated with greater overall impairment on the CGAS at admission $(P=0.017)$, and higher levels of aggression $(P=0.001)$ and externalising behaviour $(P=0.001)$ on the SNASA.

Table 4 shows the best equations from the multiple regression analyses using the index admission cost as the dependent variable. Equation A includes only the variables relating to the young people. A higher CGAS score (better functioning) at admission is associated with lower treatment costs, as indicated by the negative co-efficient. Age less than 13 years and prior school exclusion also reduces the index admission costs. This last finding is perhaps 
Table 1 Service use and costs (6 months) before and after treatment
${ }^{a}$ Includes services used by more than $5 \%$ of sample at either period

\begin{tabular}{|c|c|c|}
\hline Service $^{\mathrm{a}}$ & $\begin{array}{l}\text { Baseline }(n=132) \\
\%(n) \text { using service }\end{array}$ & $\begin{array}{l}\text { Follow-up }(n=90) \\
\%(n) \text { using service }\end{array}$ \\
\hline School and education services & $92 \%(122)$ & $81 \%(73)$ \\
\hline School & $87 \%(115)$ & $83 \%(75)$ \\
\hline Home tuition & $5 \%(7)$ & $11 \%(10)$ \\
\hline Educational psychologist & $22 \%(29)$ & $8 \%(7)$ \\
\hline Educational welfare officer & $9 \%(12)$ & - \\
\hline Special needs education coordinator & $23 \%(30)$ & - \\
\hline Nurse/medical professionals & $8 \%(11)$ & $4 \%(4)$ \\
\hline After school club & $8 \%(10)$ & - \\
\hline Mean cost per user of school and educational services (SD) & $£ 2,593(3,450)$ & $£ 4,262(6,825)$ \\
\hline Hospital services & $57 \%(75)$ & $40 \%(36)$ \\
\hline Inpatient stays & $39 \%(51)$ & $20 \%(18)$ \\
\hline Accident and emergency attendances & $20 \%(26)$ & $26 \%(23)$ \\
\hline Outpatient clinics & $23 \%(31)$ & $7 \%(6)$ \\
\hline Day hospital & $6 \%(8)$ & - \\
\hline Mean cost per user of hospital care (SD) & $£ 2,204(2,457)$ & $£ 3,755(6,804)$ \\
\hline Community health services & $82 \%(108)$ & $78 \%(70)$ \\
\hline General practitioner & $60 \%(79)$ & $56 \%(50)$ \\
\hline Optician & $20 \%(27)$ & $27 \%(24)$ \\
\hline Dentist & $45 \%(59)$ & $51 \%(46)$ \\
\hline Paediatrician & $18 \%(24)$ & $7 \%(6)$ \\
\hline Mean cost per user of community health (SD) & $£ 187(212)$ & $£ 81(88)$ \\
\hline Community mental health services & $49 \%(65)$ & $63 \%(57)$ \\
\hline Family therapist & $16 \%(21)$ & - \\
\hline Individual therapist & $25 \%(33)$ & $19 \%(17)$ \\
\hline Psychiatrist & $8 \%(10)$ & $33 \%(30)$ \\
\hline Psychologist & $5 \%(6)$ & $11 \%(10)$ \\
\hline Counselling & $2 \%(3)$ & $6 \%(5)$ \\
\hline Child guidance clinic & $6 \%(8)$ & - \\
\hline Mean cost per user of community mental health (SD) & $£ 581(1,044)$ & $£ 661(1,031)$ \\
\hline Social care services & $27 \%(36)$ & $32 \%(29)$ \\
\hline Social worker & $22 \%(29)$ & $22 \%(20)$ \\
\hline Mean cost per social care user (SD) & $£ 434$ (946) & $£ 564$ (872) \\
\hline
\end{tabular}

surprising as exclusions usually occur when the young person's behaviour is such that it cannot be contained by the school and suggests relatively high needs. However, $66 \%$ of the school-excluded young people also had high pre-admission externalising behaviour scores, and young people who had higher levels of externalising behaviour pre-admission were found to have shorter lengths of stay [18]. Shorter hospitalisations for patients with disruptive behaviour were found in an earlier study of admission length predictors [6].

The young people's characteristics and pre-admission measures "explained" only $11 \%$ of the variation in admission costs. Neither CGAS or SNASA scores at hospital discharge nor the change scores (baseline to discharge) improved the adjusted $R^{2}$. However, the identifier for Ward 4 , a child ward, raised the proportion of variance explained to nearly a fifth (Equation B, Table 4). Twenty young people were treated in this ward. Average (unadjusted) admission costs were around $£ 8,500$ higher than in other wards ( $\mathrm{CI}=4,929,12,141)$. The cost per day is close to the mean for all wards, but on average it has the longest admission (Table 2). Notably, nearly half of the patients in this ward had been excluded from school prior to admission, compared to less than a third in other wards. It may be that this ward was prepared to retain these difficult-to-treat children for longer, thus increasing the admission cost.

Costs, needs and outcomes at follow-up

Table 1 also allows comparison of the service use rates pre-admission and in the 6 months leading to the follow-up interviews. The slightly lower proportion attending school 
Table 2 Costs of index admission, 2001-2002 prices

\begin{tabular}{llrrrr}
\hline Ward and description & Cost per day & $N$ & \multicolumn{2}{l}{ Mean (range) no. of days } & $\begin{array}{l}\text { Admission costs (days spent } \\
\text { in the ward): mean (SD) }\end{array}$ \\
\cline { 5 - 6 } & & & $\begin{array}{l}\text { Admission } \\
\text { to discharge }\end{array}$ & $\begin{array}{l}\text { Days spent } \\
\text { in the ward }\end{array}$ & \\
\hline 1. Adolescent/north & $£ 277$ & 15 & $121(30-354)$ & $94(26-253)$ & $£ 26,064(16,142)$ \\
2. Child/north & $£ 249$ & 17 & $98(36-455)$ & $73(26-325)$ & $£ 21,915(21,549)$ \\
3. Child/north & $£ 299$ & 17 & $131(36-332)$ & $100(26-237)$ & $£ 26,081(17,867)$ \\
4. Adolescent/north & $£ 261$ & 20 & $161(38-354)$ & $124(27-303)$ & $£ 31,041(19,325)$ \\
5. Adolescent/south & $£ 297$ & 21 & $112(37-295)$ & $88(26-253)$ & $£ 26,158(14,484)$ \\
6. Adolescent/south & $£ 245$ & 12 & $127(51-288)$ & $96(36-206)$ & $£ 23,521(11,202)$ \\
7. Child/south & $£ 176$ & 19 & $42(25-103)$ & $33(18-74)$ & $£ 5,775(2,347)$ \\
8. Child/south & $£ 289$ & 10 & $158(14-346)$ & $135(10-297)$ & $£ 39,115(26,830)$ \\
Total & & 131 & $116(14-455)$ & $90(10-325)$ & $£ 24,123(18,674)$ \\
\hline
\end{tabular}

Table 3 Associations between patient characteristics and index admission costs

\begin{tabular}{llll}
\hline Young person... $(n)$ & Diff. & CI $^{\mathrm{a}}$ & $P$ value \\
\hline Was in children's ward (68 vs. 63) & $-£ 7,798$ & $-13,716,-1,592$ & 0.016 \\
Was younger than 13 years (63 vs. 68) & $-£ 8,641$ & $-14,373,-2,379$ & 0.008 \\
Was excluded from school $^{\mathrm{b}}$ (91 vs. 36) & $-£ 8,166$ & $-14,106,-1,527$ & 0.024 \\
\hline
\end{tabular}

${ }^{a}$ From the bootstrap analysis, 1,000 repetitions

${ }^{b}$ In the year prior to baseline interview

Table 4 Estimated cost function for index admission

\begin{tabular}{|c|c|c|c|c|c|c|}
\hline \multirow[t]{2}{*}{ Characteristic } & \multicolumn{3}{|l|}{ Equation $\mathrm{A}$} & \multicolumn{3}{|l|}{ Equation B } \\
\hline & Co-efficient & SE & $P$ & Co-efficient & $\mathrm{SE}$ & $P$ \\
\hline Constant & $43,517.40$ & $5,700.51$ & 0.000 & $42,911.48$ & $5,494.76$ & 0.000 \\
\hline Score on CGAS & -320.03 & 116.24 & 0.007 & -314.21 & 112.00 & 0.006 \\
\hline Aged under 13 years & $-7,708.09$ & $3,001.04$ & 0.011 & $-10,392.90$ & $3,008.70$ & 0.001 \\
\hline Child excluded $^{\mathrm{a}}$ & $-7,176.44$ & $3,349.21$ & 0.034 & $-8,446.54$ & $3,250.42$ & 0.011 \\
\hline \multirow[t]{2}{*}{ Ward 4} & & & & $13,853.00$ & $4,299.01$ & 0.002 \\
\hline & \multicolumn{3}{|c|}{$\begin{array}{l}N=125, R^{2}=0.132, \text { Adj } R^{2}=0.110, F=6.112 \\
\quad(P=0.001)\end{array}$} & \multicolumn{3}{|c|}{$\begin{array}{l}N=125, R^{2}=0.201, \text { Adj } R^{2}=0.174, F=7.536 \\
\quad(P<0.001)\end{array}$} \\
\hline
\end{tabular}

${ }^{\mathrm{a}}$ Excluded from school in the year prior to baseline interview

was mainly due to adolescents approaching school leaving age (all non-attenders were over 15.4 years old), but there was also a general reduction in the use of education support services. In contrast, overall education costs rose, mainly due to moves from primary to secondary or to special needs school, although attendance had improved for 13 young people. Utilisation rates of community-based mental health services appear to have increased, in contrast to the decrease in use of outpatient clinics, GPs and paediatricians. This perhaps implies access post-admission to more appropriate supports [16], although the sporadic service use patterns do not allow us to test this statistically. Three young people had been in contact with the police prior to the follow-up interview, whereas no youth justice contacts were recorded pre-admission.

For the 74 young people for whom data are available for all three periods, total support costs for the 6 months prior to follow-up were on average $£ 5,931$ per child (SD 7,623). Education services continued to bear most of the support costs (65\%), followed by hospital (23\%) and community mental health $(8 \%)$. Observed costs for four of the five service groups (see Table 1) and total support costs were higher than for the pre-admission period, but significant differences over time were only found for community health services (1\% of total costs; $P<0.001)$. 
Table 5 Associations between patient characteristics and costs at follow-up

\begin{tabular}{llll}
\hline Characteristics pre-admission & $P$ value & Characteristics at discharge & $P$ value \\
\hline Household income source $^{\mathrm{a}}$ & 0.004 & In child or adolescent unit $^{\mathrm{a}}$ & CGAS change T1-T3 $^{\mathrm{b}}$ \\
Has had at least one life event $^{\mathrm{a}}$ & 0.012 & \\
Number of life events $^{\mathrm{b}, \mathrm{c}}$ & 0.006 & \\
Aged below 13 years $^{\mathrm{a}}$ & 0.029 & \\
CGAS total score $^{\mathrm{b}}$ & 0.003 & \\
\hline
\end{tabular}

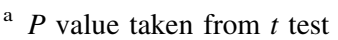

${ }^{\text {b }} P$ value taken from anova

${ }^{\mathrm{c}}$ No. of life events $=0$, one life event $=1$, two or more life events $=2$. Only two sample members had $>2$ life events in the year prior to the baseline interview

Table 6 Estimated cost function for follow-up support costs

\begin{tabular}{lcrc}
\hline Characteristics $^{\mathrm{a}}$ & Co-efficient & \multicolumn{1}{l}{ SE } & \multicolumn{1}{l}{$P$} \\
\hline Constant & $9,056.52$ & $3,561.41$ & 0.013 \\
Score on CGAS & -230.45 & 64.25 & 0.001 \\
Main income from employment & $4,859.04$ & $1,800.61$ & 0.009 \\
Number of life events & $3,099.98$ & $1,100.64$ & 0.006 \\
Aged under 13 years & $3,262.31$ & $1,624.60$ & 0.049 \\
$N=70, R^{2}=0.342$, Adj $R^{2}=0.302, F=(4,65) 8.45, P<0.000$
\end{tabular}

a All variables are from baseline assessments

b Variable coded no life events $=0$, one $=1$, two or more life events $=2$ as only two young people in this sample had more than two life events in the year prior to the baseline interview

Total support costs at follow-up ranged between $£ 19$ for the 6-month-period and $£ 29,722$. Table 5 shows that preadmission measures of life events, lower CGAS score and the families' main source of income coming from earnings were all significantly associated with higher follow-up costs. The young person's age was also positively associated with costs, in contrast to the findings for the index admission, as was the change in the CGAS score on discharge. With regard to the multiple regression analyses, four variables explain just over a third of the cost variation (Table 6). Pre-admission measures of the child and family characteristics appear particularly important; younger age of child, having an income from earnings and more life events pre-admission all raise support costs. Higher CGAS scores (better functioning) are again associated with lower costs. No service-related measures entered the equation.

\section{Discussion}

This study provides some of the first evidence on the costs of psychiatric admissions for young people, the subsequent costs as they are supported in the community and the extent to which costs vary in response to young people's circumstances. There are limitations in the design and the data.
A larger sample, for example, may have produced better results, but as far as possible, the statistical techniques used help ensure robust findings. The length of stay data are similar to that found nationally $[1,28]$. Although evidence for cost-effectiveness is sorely needed, such a study design was not possible. While there has been some growth in alternatives to inpatient psychiatric services over the past 5 years (http://www.camhsmapping.org.uk), at the time of the study there was no generally available comparator service.

The study shows that on average an inpatient admission lasts around 4 months at a cost of just over $£ 24,000$. The range around this mean is wide, and is to be expected, given the variation of young people's circumstances. The mean annual support costs for 56 young people with complex mental health needs and considered "most concerning" by the Manchester children's service agencies were estimated at $£ 52,000$ [10]. Only two young people in that sample were admitted to psychiatric inpatient units, although $60 \%$ were in social services or educational residential provisions ([10] p. 174). After 12 months, the mean number of problems and health needs were unchanged. The current study found significant improvements in symptoms and health needs associated with the index admission to levels commensurate with usual practice in communitybased CAMH teams. These improvements were sustained at the 1-year follow-up [18] despite considerably lower and less expensive levels of support.

Costs were a little different between the two community interviews in this study (pre-admission and follow-up), suggesting few immediate down-stream savings from admission. However, the proportion of cost variation explained at follow-up was higher at just over a third, and the results suggest that resources were probably better targeted on needs after admission. Inpatient units try to link patients to more appropriate supports based on a better understanding of needs at discharge. These results provide some evidence that they do so. However, the pre-admission measures of characteristics and circumstances are stronger predictors of follow-up costs than the hospital discharge 
measures, suggesting that the former have a more pervasive influence than the psychiatric or health needs that specialist metal health services aim to address. Our comprehensive cost estimation approach reflects inputs from the many other supports that will have an impact on young people's welfare.

There are three points that commissioners should consider. First, the relatively high cost for inpatient admissions has to be balanced against the strong association between longer inpatient stays and better health gain [18]. It is, however, the difficulty in predicting admission cost that underscores the need for care to be taken as national tariffs are developed for these specialised services. The complexity of this task is mirrored in studies trying to predict the length of stay for reimbursement mechanisms in the USA [6, 7] and more recently in Germany [20]. While we know more about the usual admission length in England, we still know little about how long an admission should be to generate optimal outcomes for particular groups of young people. Thus, most countries have introduced separate mechanisms to adjust tariffs for highly complex cases and highly specialised care [14].

Second, more information is needed about ways to use this high-cost CAMHS resource to its best effect. Would a planned sequence of short admissions achieve the same outcomes or would an improved bridging service facilitate earlier discharge? Are there ways of intensifying specific in-ward interventions for certain groups of young people? How should treatment be provided for the small number of young people with high levels of externalising behaviour, probably those who have already been excluded from school? The success of treatment depends in part on how well patients make an alliance on the ward [18], but such relationships are often difficult for these children. So poorer longer-term outcomes, and indeed high future support costs, may well result [29]. The low evidence base in CAMHS means that these questions may take some years to be answered.

Finally, the evidence from this study provides a benchmark for considerations about some of the newer community-based alternatives to inpatient treatment. Multi-systemic therapy, home-based treatment, wraparound supports and other intensive community-based interventions are increasingly becoming available, but the UK evidence base, particularly on cost-effectiveness, is thin. Such services should be purchased, if they can be shown to generate as good or better outcomes (for similar groups of children) as that found in this study and if shown to do this at the same or lower cost. It is likely that a range of residential, outreach, community and home-based tier 4 interventions will serve the population best [27]. Spending less on inpatient treatment may release resources for other CAMH services, but this should not be at the expense of poorer outcomes for those with serious psychiatric problems for whom inpatient treatment has been shown to be helpful.

Acknowledgments We would like to acknowledge the input from other members of the research team. In particular, our thanks are extended to Leo Kroll at the Royal Manchester Children's Hospital, Jackie Briskman and Catherine Tobias. We are also grateful to the staff in the study wards, the young people and their parents and carers for their time and their commitment to the study. The Department of Health commissioned the broad area and aims of the investigation, but had no influence on the method, measures, data analysis, interpretation or write-up. The authors are independent from the funder.

\section{References}

1. Barnes D, Wistow G, Dean R, Foster B (2006) National child and adolescent mental health service mapping exercise 2005. University School of Applied Social Sciences, Durham

2. Beecham J (1995) Collecting and estimating costs. In: Knapp M (ed) The economic evaluation of mental health care. Arena, Aldershot, pp 157-174

3. Beecham J, Knapp M (2001) Costing psychiatric interventions. In: Thornicroft $\mathrm{G}$ (ed) Measuring mental health needs. Gaskell, London, pp 200-224

4. Beecham J, Chisholm D, O'Herlihy A, Astin J (2003) Variations in the costs of child and adolescent psychiatric inpatient units. $\mathrm{Br}$ J Psychiatry 183:220-225

5. Beecham J, Chisholm D, O'Herlihy A (2002) The costs of child and adolescent psychiatric inpatient units. In: Netten A, Curtis L (eds) Unit costs of health and social care 2002. University of Kent PSSRU, Canterbury, pp 21-23

6. Borchadt C, Garfinkel B (1991) Predictors of length of stay of psychiatric adolescent inpatients. J Am Acad Child Adolesc Psychiatry 30(6):994-998

7. Christ A, Andrews H, Tsemberis S (1989) Fiscal implications of a childhood disorder DRG. J Am Acad Child Adolesc Psychiatry 28(5):729-733

8. Curtis L (2008) The unit costs of health and social care 2008. University of Kent PSSRU, Canterbury

9. Curtis L, Netten A (2002) The unit costs of health and social care 2002. University of Kent PSSRU, Canterbury

10. Clark F, O'Malley A, Woodham A, Barratt B, Byford S (2005) Children with complex problems: needs, costs and predictors over 1 year. Child Adolesc Ment Health 10(4):170-178

11. Department of Health (2003) Specialised Services national definition set: chap. 23, specialised services for children. HMSO, London

12. Department of Health (2006) Review of commissioning arrangements for specialised services. Department of Health, London

13. Dunn G, Mirandola M, Amaddeo F, Tansella M (2003) Describing, explaining or predicting mental health care costs: a guide to regression models. Br J Psychiatry 183:398-404

14. Ettelt S, Thomson S, Nolte E, Mays N (2006) Reimbursing highly specialised hospital services: the experience of activity-based funding in eight countries. Lond Sch Hyg Trop Med, London

15. Efron B, Tibshirani R (1993) An introduction to the bootstrap. Chapman and Hall, New York

16. Foster EM (2000) Is more better than less? An analysis of children's mental health services. Health Serv Res 35(5):1135-1158

17. Green J, Kroll L, Imre D, Francis F, Begum K, Gannon L, Anson R (2001) Health gain and outcome predictors during inpatient and 
related day treatment in child and adolescent psychiatry. J Am Acad Child Adolesc Psychiatry 40:325-332

18. Green J, Jacobs B, Beecham J, Dunn G, Kroll L, Tobias C, Briskman J (2007) Inpatient treatment in child and adolescent psychiatry - a prospective study of health gain and costs. J Child Psychol Psychiatry 48(12):1259-1267

19. Harrington R, Peters S, Green J, Byford S, Woods J, McGowan R (2000) Randomised comparison of the effectiveness and costs of community and hospital based mental health services for children with behavioural disorders. Br Med J 321:1047-1050

20. Höger C, Zieger H, Presting G, Witte-Lakemann G, Specht F, Rothenberger A (2002) Predictors of length of stay in inpatient child and adolescent psychiatry; failure to validate an evidencebased model. Eur Child Adolesc Psychiatry 11(6):281-288

21. International Monetary Fund (2008) World economic outlook database April, Washington DC. http://www.imf.org/external/ pubs/weo/2008/01/wedata/index.aspx. Accessed Jan 2009

22. Kaufman J, Birmaher B, Brent D, Rao U (1997) Schedule for affective disorders and schizophrenia for school-age childrenpresent and lifetime version (K-SADS-PL): initial reliability and validity data. J Am Acad Child Adolesc Psychiatry 36:980-988

23. Knapp M (1993) Background theory. In: Netten A, Beecham J (eds) Costing community care: theory and practice. Ashgate, Aldershot
24. Knapp M (1998) Making music out of noise: the cost function approach to evaluation. Br J Psychiatry 173(suppl 36):7-11

25. Kroll L, Green J (1997) Therapeutic alliance in inpatient child psychiatry: development and initial validation of the family engagement questionnaire. Clin Child Psychol Psychiatry 2(3):431-447

26. Kroll L, Woodham A, Rothwell J, Bailey S, Tobias C, Harrington R, Marshall M (1999) Reliability of the Salford needs assessment schedule for adolescents. Psychol Med 29(4):891-902

27. McDougall T, Worrall-Davies A, Hewson L, Richardson G, Cotgrove A (2008) Tier 4 child and adolescent mental health services (CAMHS) - inpatient care, day services and alternatives: an overview of Tier 4 CAMHS provision in the UK. Child Adolesc Ment Health 13(4):173-180

28. O'Herlihy A, Worrall A, Banerjee S, Jaffa T, Hill P, Mears A, Brook H, Scott A, Whilte R, Nikolaou V, Lelliot P (2002) National Child and Adolescent Psychiatric Study (NICAPS). Royal College of Psychiatrists, London

29. Scott S, Knapp M, Henderson J, Maughan B (2001) Financial costs of social exclusion: follow-up study of anti-social children into adulthood. Br Med J 323:1-5

30. Schaffer D, Gould M, Brasic J, Ambrosini P, Fisher P, Bird H, Aluwahlia S (1983) A children's global assessment scale (CGAS). Arch Gen Psychiatry 40:228-1231 